\title{
DNA Damage and Cell Cycle Arrest Induced by Protoporphyrin IX in Sarcoma 180 Cells
}

\author{
Qing Lia, Xiaobing Wang ${ }^{a}$ Kun Zhang ${ }^{a}$ Xiujuan Lia Quanhong Liu ${ }^{a}$ Pan Wanga \\ aKey Laboratory of Medicinal Resources and Natural Pharmaceutical Chemistry, Ministry of Education, \\ National Engineering Laboratory for Resource Developing of Endangered Chinese Crude Drugs in \\ Northwest of China, College of Life Sciences, Shaanxi Normal University, Xi'an, China; ${ }^{b}$ College of Life \\ Sciences, LuDong University, Yantai, China
}

\section{Key Words}

Protoporphyrin IX • DNA damage $\bullet$ Cell cycle arrest $\bullet$ S180 cells

\begin{abstract}
Background: Porphyrin derivatives have been widely used in photodynamic therapy as effective sensitizers. Protoporphyrin IX (PpIX), a well-known hematoporphyrin derivative component, shows great potential to enhance light induced tumor cell damage. However, PpIX alone could also exert anti-tumor effects. The mechanisms underlying those direct effects are incompletely understood. This study thus investigated the putative mechanisms underlying the anti-tumor effects of PpIX on sarcoma 180 (S180) cells. Methods: S180 cells were treated with different concentrations of PpIX. Following the treatment, cell viability was evaluated by the 3-(4, 5- dimethylthiazol-2-yl)-2, 5-diphenyltetrazoliumbromide (MTT) assay; Disruption of mitochondrial membrane potential was measured by flow cytometry; The trans-location of apoptosis inducer factor (AIF) from mitochondria to nucleus was visualized by confocal laser scanning microscopy; DNA damage was detected by single cell gel electrophoresis; Cell cycle distribution was analyzed by DNA content with flow cytometry; Cell cycle associated proteins were detected by western blotting. Results: PpIX ( $\geq 1 \mu \mathrm{g} / \mathrm{ml})$ significantly inhibited proliferation and reduced viability of S180 cells in a dose-dependent manner. PpIX rapidly and significantly triggered mitochondrial membrane depolarization, AIF (apoptosis inducer factor) translocation from mitochondria to nucleus and DNA damage, effects partially relieved by the specific inhibitor of MPTP (mitochondrial permeability transition pore). Furthermore, S phase arrest and upregulation of the related proteins of P53 and P21 were observed following 12 and $24 \mathrm{~h}$ PpIX exposure. Conclusion: PpIX could inhibit tumor cell proliferation by induction of DNA damage and cell cycle arrest in the S phase.
\end{abstract}


Li et al.: PpIX Caused DNA Damage and Cell Cycle Arrest in S180 Cells

\section{Introduction}

Protoporphyrin IX, an effective compound of hematoporphyrin derivatives (HpD), has significant potential to enhance light or ultrasound induced cytotoxicity $[1,2]$. As the precursor of heme, protoporphyrin IX can be endogenously synthesized via the metabolic pathway and preferentially accumulated in rapid proliferating cancer cells due to the decreased level of ferrochelatase and the increased activity of PBGD (porphobilinogen deaminase) of tumor cells $[3,4]$. On the one hand, the endogenous protoporphyrin IX (ALAPpIX) indirectly generated by $\delta$-Aminolevulinic acid (5-ALA) has been well investigated in photodynamic theraphy (PDT) [5, 6]. On the other hand, previous study has reported the synergistic effect of ultrasound and exogenous protoporphyrin IX (PpIX) in sonodynamic therapy (SDT), in which PpIX was administrated to cells directly [7, 8].

Our previous study on the cytotoxicity induced by PpIX and ultrasound implied that, slight or even no cell damage was observed when an appropriate concentration of PpIX was applied, whereas significant cytotoxicity could be induced when the concentration of PpIX exceeded certain threshold [9]. Other experiment also showed that PpIX alone could inhibit HeLa cell proliferation even without light excitation [10]. Zawacka-Pankau et al. demonstrated there existed interactions between PpIX and p53 protein in vitro by fluorescence correlation spectroscopy; moreover they found PpIX could disrupt the p53/MDM2 (murine double minute 2) complex, lead to p53 protein accumulation and then activate cell apoptosis [11]. These findings indicated PpIX may have novel function in tumor treatment, and more attention should be given to both basic and clinical study of PpIX mediated PDT or SDT therapy. Therefore, this study further explored the anti-tumor activity of PpIX alone in the absence of light and ultrasound exposure, as well as its potential mechanisms.

Similar as PpIX, another HpD component, haematoporphyrin monomethyl ether (HMME) mediated SDT has revealed obvious S phase arrest in C6 glioma cells [12], implying porphyrins may affect cell cycle distribution. Cell cycle control is the major regulatory mechanism of cell growth $[13,14]$. DNA-damaging agents have various disruptive biological effects on cells, such as arrest cell cycle progression by activating phase-specific check points, motivate the cells to commit suicide by a controlled program known as apoptosis and so on $[15,16]$. In eukaryotes, cyclins accurately regulate the cell cycle running via binding to and activating cyclin-dependent kinases (CDKs) [17]. Cyclin-dependent kinase inhibitors (CDKI), p21 and p27 also play key roles in controlling cell cycle progression by negatively regulating CDKs activities [18]. However, there are few reports about cell cycle arrest caused by exogenous protoporphyrin IX so far, this study thus mainly focused on DNA damage and cell cycle arrest analysis, in order to further investigate the mechanisms of the toxic effect on tumor cells induced by PpIX.

\section{Materials and Methods}

Materials

Protoporphyrin IX disodium salt, 3-(4, 5-dimethylthiazol-2-yl)-2, 5-diphenyltetrazoliumbromide (MTT), 4, 6-diamidino-2-phenylindole (DAPI), cyclosporine A (CsA) were purchased from Sigma Chemical Company (St Louis, MO, USA). MitoTracker Green (MTG) was obtained from Molecular Probes (Invitrogen, CA, USA). The primary antibodies of p53, p21, $\beta$-actin, and HRP-labeled secondary antibodies were obtained from Santa Cruz Biotechnology (Santa Cruz, CA, USA). All other reagents were commercial products of analytical grade.

\section{Cell culture}

Murine sarcoma S180 (S180) cells were obtained from the Cell Bank of the Chinese Academy of Science, Shanghai, China. The cell line was cultured in RPMI-1640 (Gibco, Life Technologies, Inc., USA) supplemented with $10 \%$ fetal bovine serum (FBS, Hyclone, USA), $100 \mathrm{IU} / \mathrm{ml}$ penicillin, $100 \mu \mathrm{g} / \mathrm{ml}$ streptomycin and $1 \mathrm{mM}$ L-glutamine. Cells were maintained at $37{ }^{\circ} \mathrm{C}$ in humidified $5 \% \mathrm{CO}_{2}$ atmosphere. Cells in the exponential phase of growth were used in each experiment. 
Li et al.: PpIX Caused DNA Damage and Cell Cycle Arrest in S180 Cells

\section{PpIX treatment procedure}

In this study, the first step is to upload sufficient PpIX in S180 cells, the next step is to study cellular response to PpIX treatment. Because PpIX usually interact with serum [19], so S180 cells were co-incubated with various concentrations of PpIX in serum-free 1640 medium for 45 min to make sure PpIX rapidly enriched in S180 cells [7], then, serum was added to ensure the PpIX-loading cells in a normal cultural conditions (1640 medium $+10 \%$ serum) for different incubations as specified in the text. For inhibitory study, cyclosporine A (CsA) was added to culture medium $1 \mathrm{~h}$ prior to loading PpIX at a final concentration of $0.1 \mu \mathrm{M}$.

\section{MTT assay}

The cytotoxic activity of PpIX on S180 cells was measured using MTT assay. Briefly, the control or PpIX-loading cells at the density of $2 \times 10^{5}$ cells $/ \mathrm{ml}(100 \mu \mathrm{l})$ were seeded to 96 well culture plates, and cell viability after different incubations $(0,4,8,12,24$ and $36 \mathrm{~h})$ were determined by adding $10 \mu \mathrm{l}$ of MTT solution (5 mg/ml in PBS) to each well and the mixture was incubated for additional $4 \mathrm{~h}$ at $37^{\circ} \mathrm{C}$ in a $\mathrm{CO}_{2}$ incubator. The formazan crystals were dissolved in $100 \mu \mathrm{l} 10 \%$ SDS, $5 \%$ isobutyl alcohol, $0.01 \mathrm{~mol} / \mathrm{L} \mathrm{HCL}$ solution, and the absorbance at $570 \mathrm{~nm}$ was recorded using a micro-plate reader (BIO-TEK ELX800, USA). The cell survival rate was obtained by comparing to the control.

\section{Mitochondrial membrane potential $(\Delta \psi m)$}

The mitochondrial membrane potential $\left(\Delta \psi_{\mathrm{m}}\right)$ was measured by uptake of the mitochondrial specific lipophilic caption dye rhodamine 123. After $1 \mathrm{~h}$ of incubation post PpIX-loading, S180 cells were collected by centrifugation for $5 \mathrm{~min}$ and washed with PBS, then incubated with $2 \mu \mathrm{g} / \mathrm{ml}$ rhodamine 123 for 30 min at room temperature, washed and re-suspended in PBS buffer. Samples were immediately analyzed by a fluorescence microplate reader (Zenyth 3100, Anthos Company, Salzburg, Austria) at the excitation wavelength of $488 \mathrm{~nm}$.

\section{AIF translocation}

Since the translocation of mitochondrial protein AIF from the mitochondrion to the nucleus has been proposed to be a crucial step in mitochondrial dependent cell apoptosis [20]. So, the translocation of AIF in S180 cells after mitochondria damage was checked by immunofluorescence.

At $1 \mathrm{~h}$ post PpIX-loading, S180 cells were stained with $10 \mathrm{nM}$ MTG (with a $488 \mathrm{~nm}$ excitation and $530 \mathrm{~nm}$ emission), a well-established fluorescent probe for mitochondria. After being washed twice with cold PBS, cells were collected by centrifugation and fixed with $4 \%$ paraformaldehyde, washed three times and permeabilized with $0.2 \%$ TritonX-100 in PBS at room temperature for $10 \mathrm{~min}$. The cells were blocked with $0.5 \%$ bovine serum albumin and probed over night with anti-AIF primary antibody (Cell Signaling Technology) at $4^{\circ} \mathrm{C}$. The cells were washed with PBS and stained with TRITC-conjugated secondary antibody (with a $543 \mathrm{~nm}$ excitation and $620 \mathrm{~nm}$ emission). Lastly, nuclei were counterstained with DAPI (with a 405 $\mathrm{nm}$ excitation and $454 \mathrm{~nm}$ emission) staining. Cells were imaged with a Leica TCS SP5 inverted confocal laser scanning microscope (Wetzlar, Germany) equipped with Argon/HeNe laser light sources. In multichannel imaging, photo-multiplier sensitivities and offsets were set to a level at which bleed through effects from one channel to another were negligible.

\section{Single cell gel electrophoresis of DNA damage}

The alkaline comet assay was applied to evaluate DNA damage in S180 cells. Briefly, after different incubation times post PpIX-loading, cells were collected, mixed with low melting point agarose, and added into the agarose covered-slides, then covered by glass coverslips to solidify on ice. After removing the glass coverslips, the slides were placed in the ice-cold lysis buffer $\left(2.5 \mathrm{M} \mathrm{NaCl}, 100 \mathrm{mM} \mathrm{Na}{ }_{2}\right.$ EDTA, $10 \mathrm{mM}$ Tris-HCl, $1 \%$ Triton X-100 and $10 \%$ DMSO, $\mathrm{pH} 10$ ) at $4{ }^{\circ} \mathrm{C}$ overnight. The slides were then incubated in a horizontal gel electrophoresis apparatus filled with fresh, cold electrophoresis buffer $\left(300 \mathrm{mM} \mathrm{NaOH}, 1 \mathrm{mM} \mathrm{Na} \mathrm{E}_{2} \mathrm{EDTA}, \mathrm{pH}\right.$ $>13$ ) for $30 \mathrm{~min}$ at $4^{\circ} \mathrm{C}$ to unwind DNA completely prior to electrophoresis. After electrophoresis, the slides were transferred to the neutralization buffer for $15 \mathrm{~min}$ and then dehydrated in ethyl-alcohol for several times. Nuclear DNA were stained with ethidium bromide $(20 \mu \mathrm{g} / \mathrm{ml})$ and observed under fluorescence microscope. CASP software was used to analyze the obtained images. 
Fig. 1. Effects of different concentration of PpIX on the viability of S180 cells after variable incubation times. Exponentially growing cells were treated with the indicated concentration of PpIX, cell viability was determined using MTT assay at different time points after PpIXloading. Data are means \pm SE from three independent experiments.

Fig. 2. Effect of PpIX on the mitochondrial membrane potential of S180 cells. After $1 \mathrm{~h}$ of incubation, PpIX-treated S180 cells was stained with rhodamine 123 (Rho 123) to check the mitochondria potential as described in the methods. The fluorescence intensity of Rho 123 can be proportioned to the mitochondria potential. Data are means \pm SE from at least three independent experiments. ${ }^{*} \mathrm{p}<0.05, \quad{ }^{* *} \mathrm{p}<0.01 \quad$ compared with control.
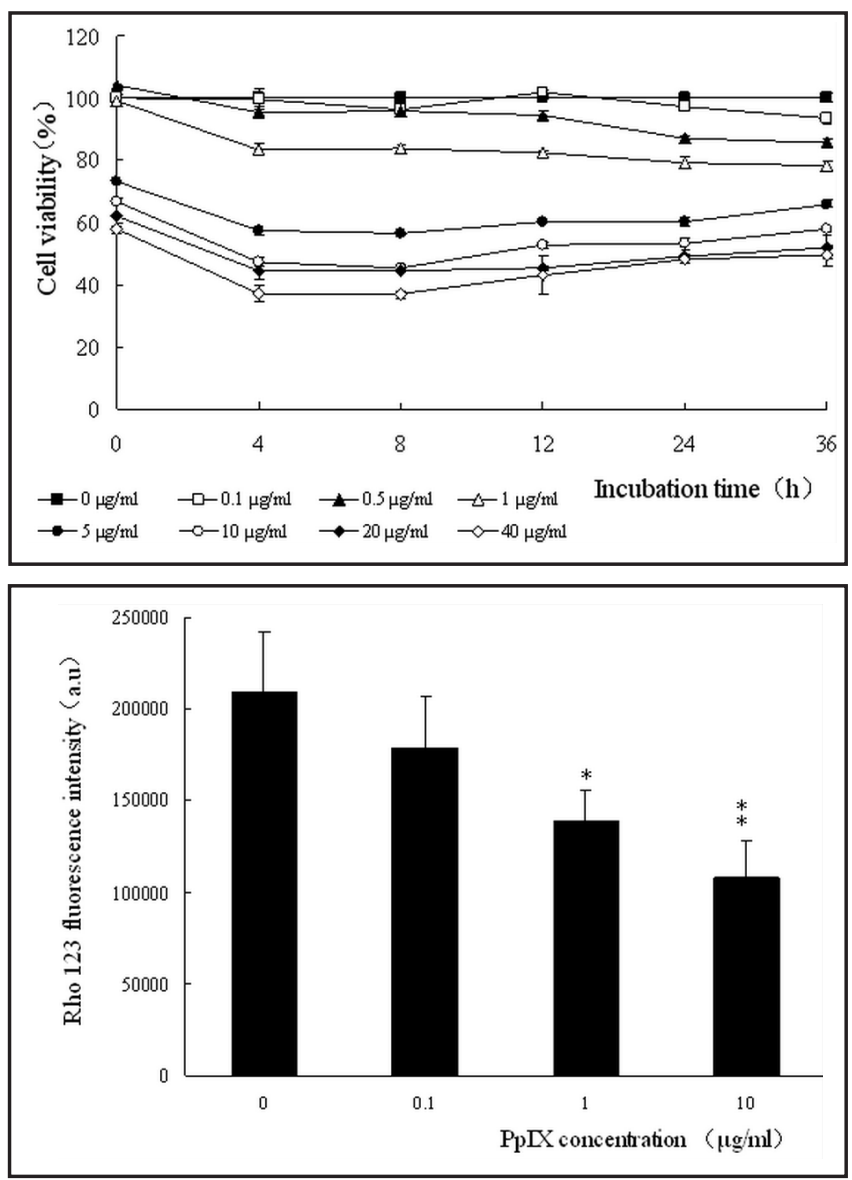

Flow cytometry analysis of cell cycle

At different time points post PpIX-loading, cells were washed twice with ice-cold PBS and fixed by $70 \%$ ethanol at $-20^{\circ} \mathrm{C}$ for $24 \mathrm{~h}$. Cells were further washed twice with ice-cold PBS and incubated with RNAase $(100 \mu \mathrm{g} / \mathrm{ml})$ for 30 minutes, then stained with propidium iodide (PI, $50 \mu \mathrm{g} / \mathrm{ml}$ ) for 10 minutes. Cell cycle phase analysis was performed using a FACS Calibur (Becton\&Dickinson, USA). 10000 cells per sample were collected and analyzed by using the fit analysis program.

\section{Western blotting}

At $24 \mathrm{~h}$ post PpIX loading, S180 cells were washed by PBS and lysed in $100 \mu$ of PIRA buffer (50 mM Tris-HCl (pH7.4), $150 \mathrm{mM} \mathrm{NaCl} 1 \mathrm{mM}$ EDTA, 1\% Triton X-100, 1\% sodium deoxycholate, 0.1\% SDS, $1 \mathrm{mM}$ PMSF, $1 \mathrm{mM}$ leupeptin and $0.01 \mathrm{mM}$ aprotinin). The lysates were subsequently collected and stored at $-20^{\circ} \mathrm{C}$ until further use. The protein content of the lysate was measured using BCA reagent. Supernatant samples containing about $40 \mu \mathrm{g}$ of total protein were resolved by $8-15 \%$ SDS-PAGE depending on the target protein sizes, and were transferred onto an nitrocellulose membrane (Millipore, USA) and probed with anti-p53 and anti-p21 antibodies. The bound primary antibodies were then tagged with horseradish peroxidaselabeled secondary antibodies at room temperature for $1 \mathrm{~h}$ and the immune complexes were detected by enhanced chemiluminescence (ECL) system. Anti- $\beta$-actin was used to ensure equal loading.

\section{Statistical analysis}

Data were presented as mean \pm SE (standard error) from at least three independent experiments. Differences among the groups were assessed with one-way analysis of variance, $p<0.05$ was considered to be significant and $\mathrm{p}<0.01$ was considered to be extremely significant. 
Fig. 3. AIF redistribution in S180 cells after PpIX treatment. At $1 \mathrm{~h}$ after PpIXloading, the translocation of AIF (red fluorescence) in S180 cells was analyzed using confocal microscopy. The mitochondria and nucleus were also specially labeled with MTG (green fluorescence) and DAPI (blue fluorescence), respectively. The merge channel shows clearly the overlapping of three fluorescences.

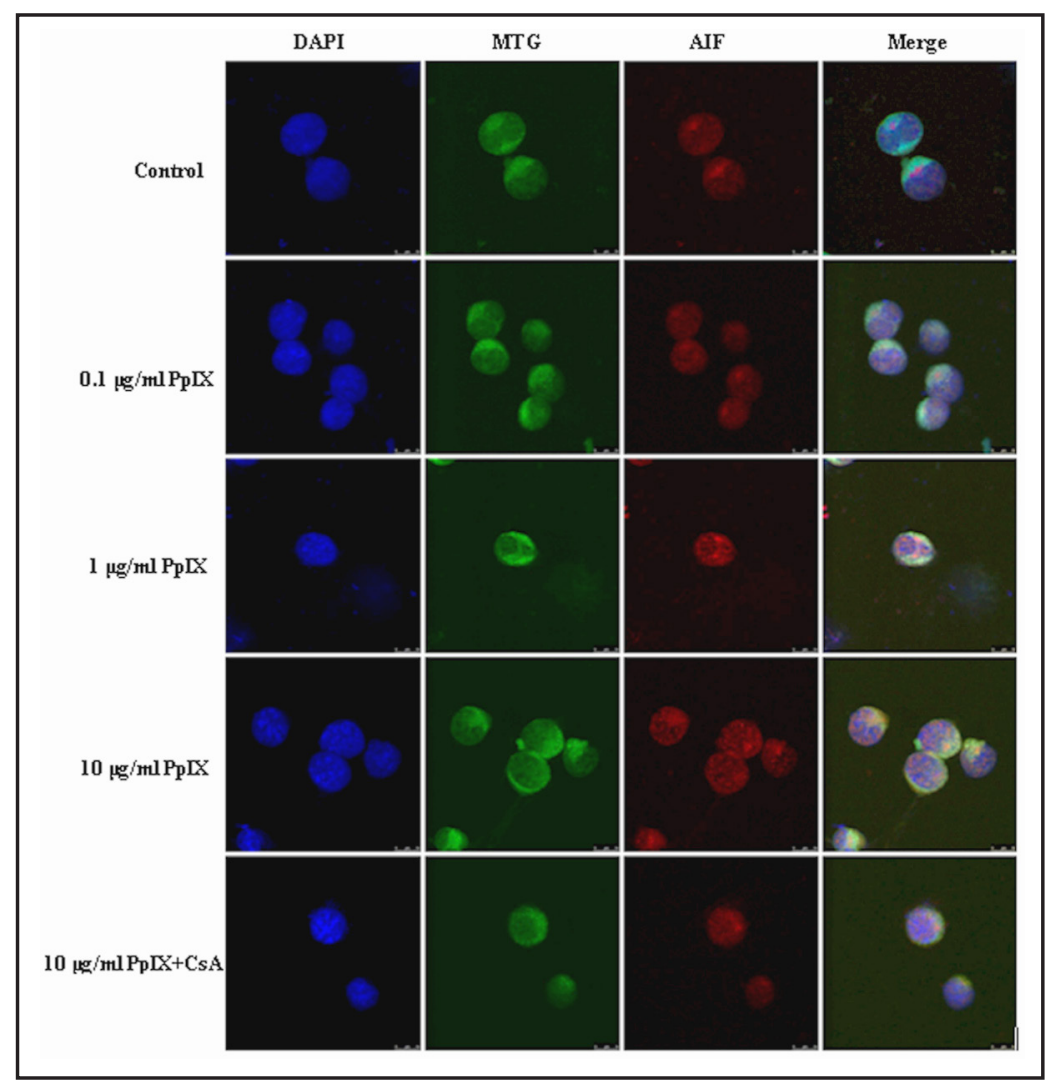

\section{Results}

\section{MTT assay}

In order to determine the anti-proliferative effect of PpIX, we assessed the viability of S180 cells treated by different concentration of PpIX $(0.1-40 \mu \mathrm{g} / \mathrm{ml})$ after variable incubations $(0,4,8,12,24$, and $36 \mathrm{~h})$. The results (Fig. 1) showed that the inhibitory effect of PpIX on S180 proliferation was in a time and dose-dependent manner. A slight cytotoxicity was shown when PpIX was $<1 \mu \mathrm{g} / \mathrm{ml}$ and significant viability loss was detected when PpIX was $\geq 1 \mu \mathrm{g} / \mathrm{ml}$. When the incubation time was less than $4 \mathrm{~h}$, the cell viability was quickly decreased, showing a typical PpIX-dose dependent manner. This tendency slightly changed until $8 \mathrm{~h}$ of incubation, then two different phenomena occurred: the cell viability basically sustained the current level when PpIX was $<5 \mu \mathrm{g} / \mathrm{ml}$, while which then slightly increased when PpIX was $\geq 10 \mu \mathrm{g} / \mathrm{ml}$.

\section{Mitochondrial membrane potential $(\Delta \psi m)$}

The increasing evidence that changes in $\Delta \psi \mathrm{m}$ are linked to the integrity of mitochondrial membrane led us to examine the influence of PpIX on $\Delta \psi \mathrm{m}$ of S180 cells. As illustrated in Figure 2, after $1 \mathrm{~h}$ incubation post PpIX loading, S180 cells showed a loss of $\Delta \psi \mathrm{m}$ as revealed by reduced rhodamine123 fluorescence intensity. The mean rhodamine123 fluorescence declined from $\mathrm{Ma}=209270$ (control) to $\mathrm{Mb}=108301(10 \mu \mathrm{g} / \mathrm{ml}$ PpIX treated). Compared with control, $0.1 \mu \mathrm{g} / \mathrm{ml}$ PpIX did not cause much loss of $\Delta \psi \mathrm{m}$ ( $\mathrm{p}>0.05)$, while $1 \mu \mathrm{g} / \mathrm{ml}$ PpIX induced obvious $\Delta \psi \mathrm{m}$ loss $(\mathrm{p}<0.05)$, and the $\Delta \psi$ decreasing became more significant when the concentration of PpIX was up to $10 \mu \mathrm{g} / \mathrm{ml}(\mathrm{p}<0.01)$.

\section{Determination of AIF translocation}

DNA damage could be induced by AIF releasing from mitochondria to nucleus when the mitochondrial damage occurred. So, the AIF translocation was detected by confocal laser scanning microscopy at $1 \mathrm{~h}$ post PpIX-loading. The merge channel in Figure 3 showed the AIF 
Fig. 4. DNA damage of S180 cells after PpIX treatment. The DNA damage was detected by single cell gel eletrophoresis when cells were loaded with different concentration of PpIX, and visualized under fluorescent microscope. The obtained images were analyzed with tail length by CASP software. At least 100 cells were analyzed in each sample.

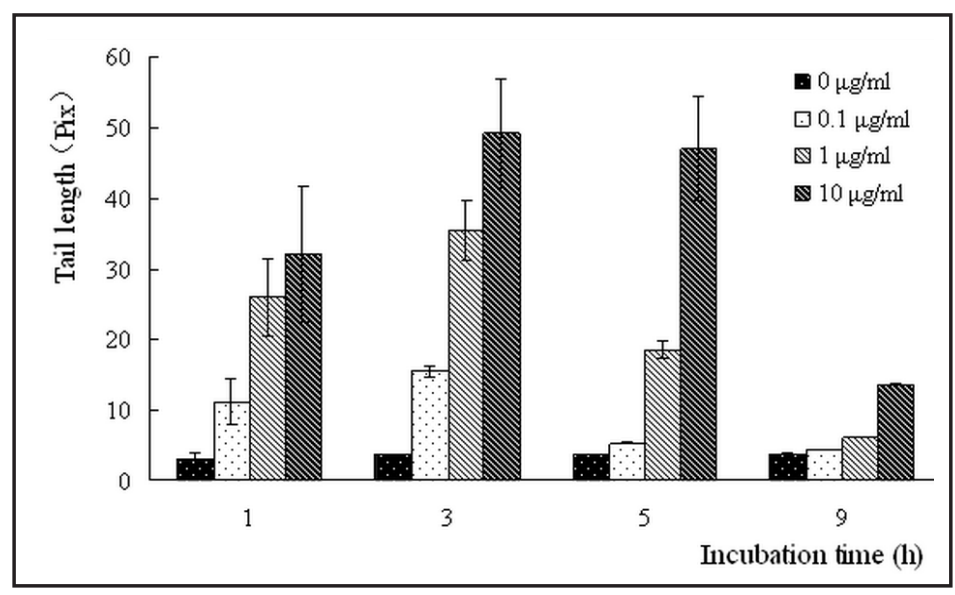

Fig. 5. Inhibitory effect of CsA on DNA damage of S180 cells caused by different concentration of PpIX. DNA damage in S180 cells was measured as described in the methods by the comet assay with or without $0.1 \mu \mathrm{M}$ CsA preincubation before PpIX-loading. The obtained images were analyzed with tail length by CASP software. At least 100 cells were analyzed in each sample. ${ }^{*} \mathrm{p}<0.05$, $* * \mathrm{p}<0.01$.

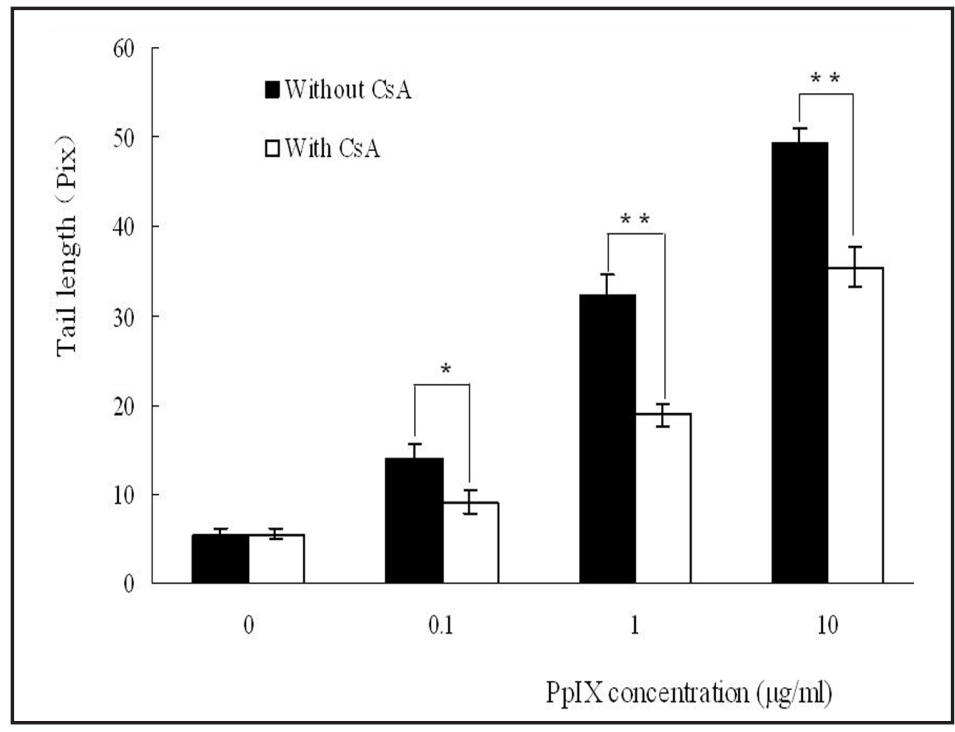

red fluorescence could not completely overlap with MTG (mitochondria special dye) green fluorescence and was partly correspondent with DAPI blue fluorescence when PpIX was 1 and $10 \mu \mathrm{g} / \mathrm{ml}$, suggesting AIF partially trans-located from mitochondria to nucleus under such concentration of PpIX stress. In contrast, AIF red fluorescence corresponded well with MTG green fluorescence and did not show much overlapping with DAPI in control and $0.1 \mu \mathrm{g} /$ ml PpIX groups. In addition, the translocation of AIF from mitochondria to nucleus induced by higher concentration of PpIX could be mostly suppressed by cyclosporine A, which is the special inhibitor of mitochondria permeability transition pore.

\section{Single cell gel electrophoresis of DNA damage}

In this study, the comet assay was used to investigate the DNA damage induced by PpIX in S180 cells after different incubations. The damaged DNA migrated out of the nucleus and then formed a tail, which can be quantified by image analysis. According to the tail length analysis in Figure 4, cells exposed to PpIX resulted in an increased DNA migration in a doseand incubation time-dependent manner. DNA damage stimulated by different concentration of PpIX continued to increase until $3 \mathrm{~h}$ post PpIX-loading, which then slightly decreased after $5 \mathrm{~h}$ of incubation, and rapidly reduced to a very low level of the control. The result indicates DNA damage and repair occurred one after the other in S180 cells after PpIX-loading.

The most serious DNA damage at $3 \mathrm{~h}$ post PpIX-loading (Fig. 5) was obvious reduced by CsA, which specially inhibit the open of mitochondria permeability transition pore, thus suppressed some factors to release from mitochondria and subsequent enter nucleus to induce DNA damage. 
Li et al.: PpIX Caused DNA Damage and Cell Cycle Arrest in S180 Cells

Table 1. Cell cycle distributions at different incubation time points after PpIX-loading

\begin{tabular}{|c|c|c|c|c|c|}
\hline $\begin{array}{l}\text { Incubation time / } \\
\text { PpIX concentration }\end{array}$ & & $12 \mathrm{~h}$ & $24 \mathrm{~h}$ & $36 \mathrm{~h}$ & $48 \mathrm{~h}$ \\
\hline \multirow{4}{*}{$0 \mu \mathrm{g} / \mathrm{ml}$ PpIX } & $\mathrm{G} 0 / \mathrm{G} 1(\%)$ & 33.10 & 56.47 & 38.53 & 27.59 \\
\hline & $S(\%)$ & 42.65 & 31.62 & 46.06 & 48.04 \\
\hline & G2/M ( \% ) & 24.25 & 11.91 & 15.59 & 24.37 \\
\hline & $\mathrm{G} 0 / \mathrm{G} 1(\%)$ & 33.97 & 54.15 & 37.24 & 27.27 \\
\hline \multirow[t]{3}{*}{$0.1 \mu \mathrm{g} / \mathrm{ml}$ PpIX } & $\mathrm{S}(\%)$ & 39.95 & 32.41 & 46.38 & 49.20 \\
\hline & G2/M ( \% ) & 22.08 & 13.45 & 16.38 & 23.53 \\
\hline & G0/G1 ( \% ) & 34.93 & 49.62 & 33.50 & 28.06 \\
\hline \multirow[t]{3}{*}{$1 \mu \mathrm{g} / \mathrm{ml}$ PpIX } & $S(\%)$ & 46.52 & 37.04 & 43.33 & 47.68 \\
\hline & $\mathrm{G} 2 / \mathrm{M}(\%)$ & 18.56 & 13.34 & 23.17 & 24.27 \\
\hline & G0/G1 ( \% ) & 34.84 & 47.56 & 30.69 & 28.65 \\
\hline \multirow[t]{3}{*}{$10 \mu \mathrm{g} / \mathrm{ml}$ PpIX } & $\mathrm{S}(\%)$ & 50.63 & 41.63 & 44.11 & 47.23 \\
\hline & $\mathrm{G} 2 / \mathrm{M}(\%)$ & 14.53 & 10.81 & 25.20 & 24.12 \\
\hline & G0/G1 ( \% ) & 27.77 & 44.82 & 32.57 & 26.63 \\
\hline \multirow[t]{3}{*}{$20 \mu \mathrm{g} / \mathrm{ml}$ PpIX } & $\mathrm{S}(\%)$ & 55.86 & 46.42 & 45.01 & 47.98 \\
\hline & G2/M ( \% ) & 18.02 & 8.76 & 22.43 & 25.39 \\
\hline & $\mathrm{G} 0 / \mathrm{G} 1(\%)$ & 27.74 & 44.15 & 35.14 & 28.13 \\
\hline \multirow[t]{2}{*}{$40 \mu \mathrm{g} / \mathrm{ml}$ PpIX } & $\mathrm{S}(\%)$ & 58.21 & 52.59 & 42.05 & 47.25 \\
\hline & $\mathrm{G} 2 / \mathrm{M}(\%)$ & 14.05 & 3.27 & 22.81 & 24.62 \\
\hline
\end{tabular}

Fig. 6. Statistically analysis of the percentage of different phases in S180 cells at $24 \mathrm{~h}$ post PpIX loading. Data are means $\pm \mathrm{SE}$ from three independent experiments.

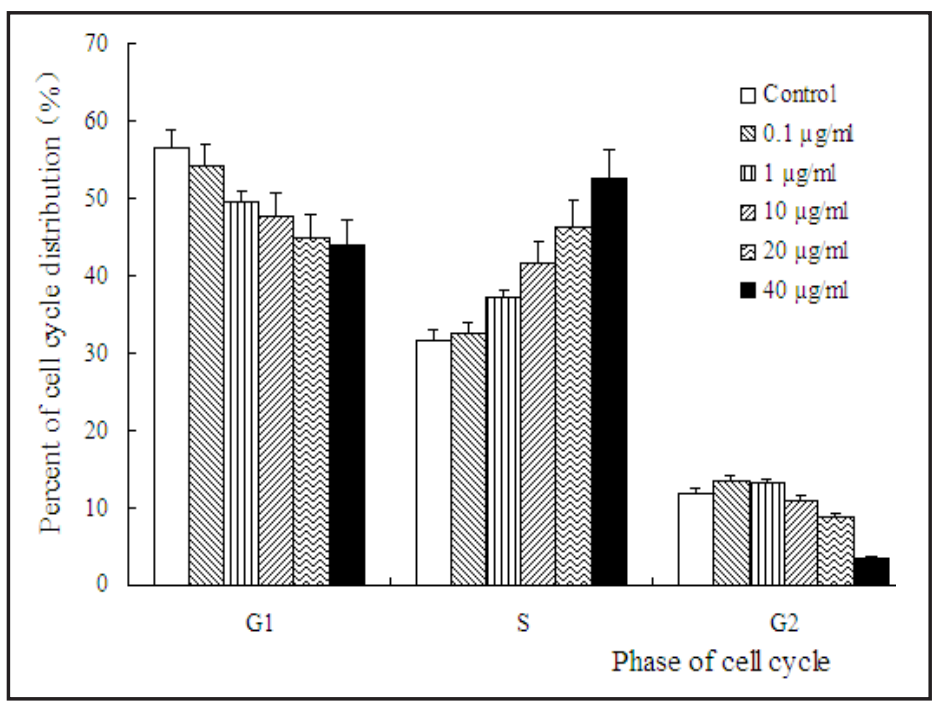

Flow cytometry analysis of cell cycle

To determine whether cell growth inhibition after PpIX treatment was related to cell cycle changes, we next examined cell cycle phase distribution by flow cytometry. When cells were loaded with various concentration of PpIX, S-phase arrest was observed in a concentration- and incubation time-dependent manner (Table 1). After $12 \mathrm{~h}$ and $24 \mathrm{~h}$ of incubation, very obvious $S$ phase arrest was observed. The percentage of $S$ phase cells increased as PpIX concentration increased. At $24 \mathrm{~h}$ post PpIX-loading, the S phase cells increased from 31.62 (control) to $52.59 \%$ when PpIX concentration was up to $40 \mu \mathrm{g} / \mathrm{ml}$ (Fig. 6). At $12 \mathrm{~h}$ post PpIX-loading, the percentage of S phase cells increased from $39.95 \%$ to $58.21 \%$ when PpIX increased from $0.1 \mu \mathrm{g} / \mathrm{ml}$ to $40 \mu \mathrm{g} / \mathrm{ml}$; Besides, there was an increasing 


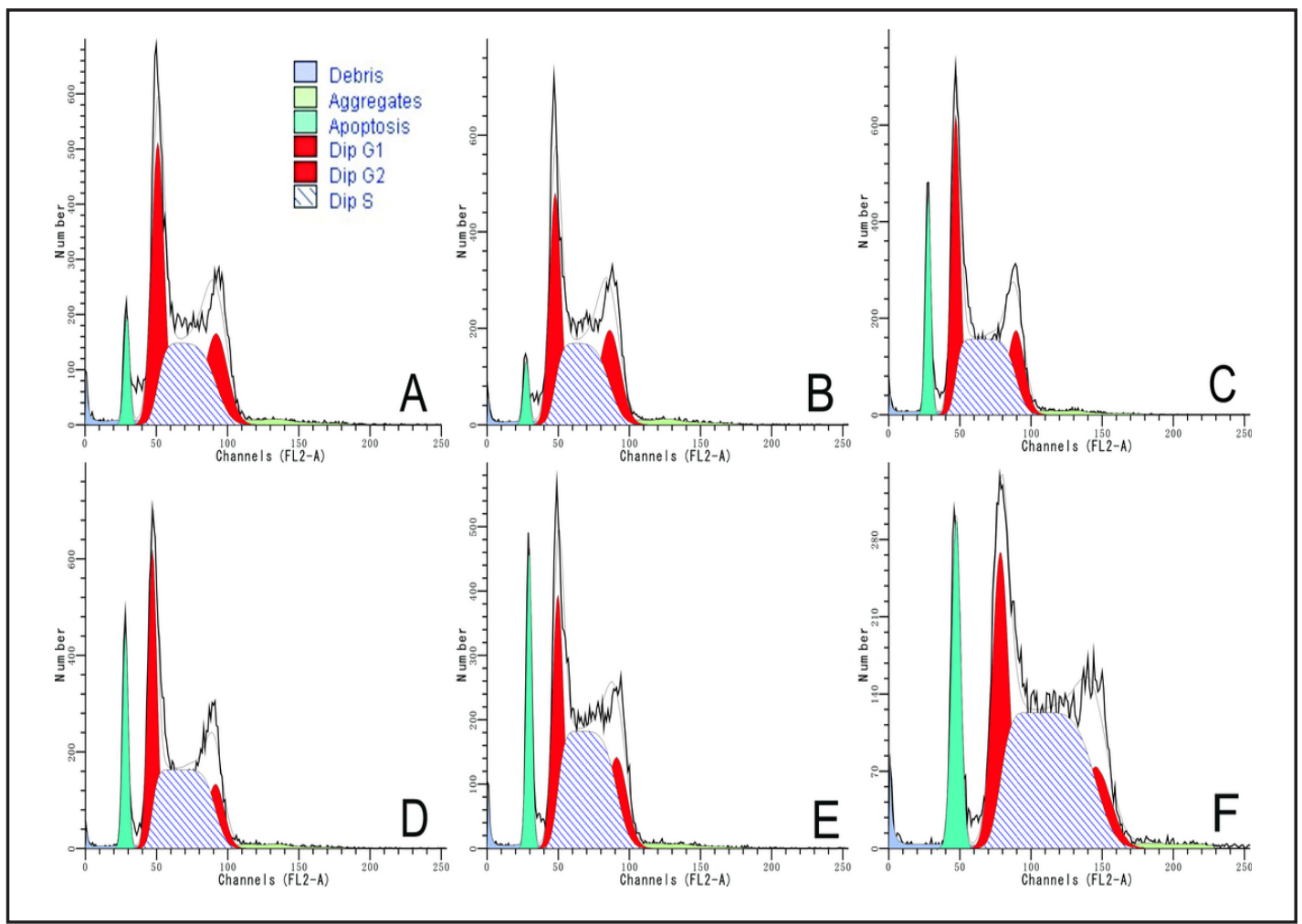

Fig. 7. Cell cycle arrest of S180 cells at $12 \mathrm{~h}$ post PpIX loading. The cell cycle distribution was detected by flow cytometry when cells were treated with the given concentration of PpIX, and the representative profiles of the cell cycle distribution were shown. (A) Untreated control; (B) $0.1 \mu \mathrm{g} / \mathrm{ml} \mathrm{PpIX;} \mathrm{(C)} 1 \mu \mathrm{g} / \mathrm{ml}$

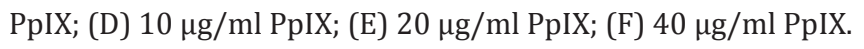

Fig. 8. Effect of PpIX on P53 and P21 expressions in S180 cells. At $24 \mathrm{~h}$ post PpIX loading, cells were collected and subjected to western blot analysis as described in the Methods. Anti- $\beta$-actin was used to ensure equal loading.

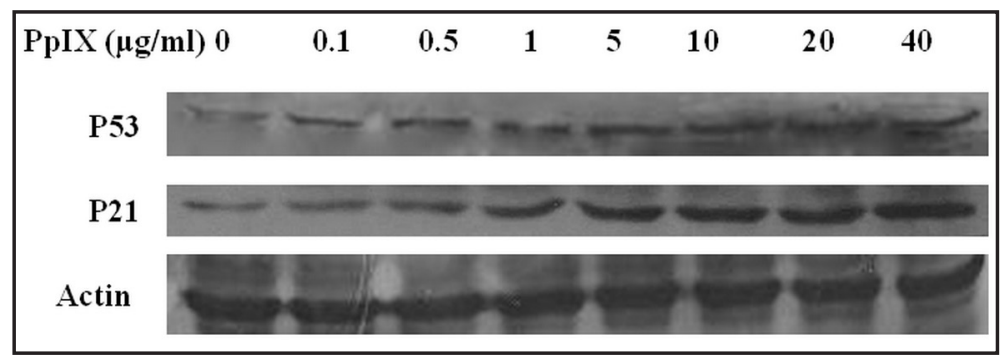

cell apoptosis index shown as Sub-G1 peak occurred (Fig. 7). However, there were no visible changes in the percentage of S phase cells when the incubation time increased to $36 \mathrm{~h}$ and 48 h, no matter what concentration of PpIX was applied (Table 1).

\section{Western blot analysis}

To further examine whether the cell cycle associated and DNA damage closely related protein expressions of P53 and P21 were changed by PpIX, an immuno-blotting analysis were performed at $24 \mathrm{~h}$ after PpIX-loading. As shown in Figure 8, the protein expressions of P53 and P21 gradually increased as PpIX concentration increased. 
Li et al.: PpIX Caused DNA Damage and Cell Cycle Arrest in S180 Cells

\section{Discussion}

As an effective sensitizer, protoporphyrin IX has been evidenced to enhance light/ ultrasound induced cytotoxicity in PDT/SDT [1, 2, 7-9]. Recent findings also revealed that the sensitizer itself could inhibit tumor proliferation [9-11], but the underlying mechanisms haven't been fully explained. Therefore, this study was to explore the anti-tumor activity of PpIX alone without any light or ultrasound exposure, as well as its potential mechanisms.

MTT assay showed that the cell viability loss depended on the PpIX dose and the incubation time (Fig. 1). The cell growth was slightly affected at low PpIX dose, only when PpIX concentration was $\geq 1 \mu \mathrm{g} / \mathrm{ml}$, obviously viability inhibition could be detected, showing a typical drug-dose dependent manner. Moreover, the cell viability decreased quickly in the first $4 \mathrm{~h}$ of incubation, and maintained relatively stable until $8 \mathrm{~h}$ of incubation, then slightly increased after $12 \mathrm{~h}$ of incubation when PpIX was $\geq 10 \mu \mathrm{g} / \mathrm{ml}$. This might be due to the metabolism of PpIX in S180 cells after its loading.

A series of responses will be launched once cell damage was initiated. DNA damage can interfere with DNA replication, transcription, chromosome segregation etc. [21]. In this study, PpIX induced DNA damage was detected by single cell gel electrophoresis, and evident DNA damage was observed in a PpIX dose- and incubation time-dependent manner. Results in Figure 4 showed the DNA damage increased until $3 \mathrm{~h}$ post PpIX-loading, then slightly decreased after $5 \mathrm{~h}$ of incubation, and rapidly reduced to a very low level after $9 \mathrm{~h}$ of incubation. The result indicated DNA damage and repair occurred one after the other in S180 cells following PpIX administration in serum-free medium and then re-suspending in complete medium, allowing PpIX release from the cell and bind to the serum in the medium. The DNA damage mentioned above was also consistent with the changing trend of the cytotoxicity of S180 cells after PpIX treatment.

DNA damage can be induced by many factors and also can result in many downstream events. AIF, as a mitochondrial apoptogenic factor, can induce apoptosis without cytochrome c mediated caspase activation [22]. In response to different apoptotic stimuli, AIF will be released into the cytosol and translocates to the nucleus where it could induce chromatin condensation and large-scale DNA fragmentation. Our previous data suggested PpIX couldn't enter the nuclei of S180 cells [7], so how did this DNA damage initiated by PpIX? We therefore inferred the DNA damage might be induced through the depolarization of mitochondrial potential and the translocation of some factors from mitochondria into nucleus. Our obtained data indicated that at $1 \mathrm{~h}$ post PpIX-loading ( $\geq 1 \mu \mathrm{g} / \mathrm{ml}$ ), the loss of $\Delta \psi \mathrm{m}$ was very significant and when the translocation of AIF from mitochondria to nucleus could be obviously observed. In addition, the above-mentioned translocation of AIF from mitochondria to nucleus was mostly suppressed when co-administration with CsA, the special inhibitor of mitochondria permeability transition pore. Accordingly, results in Figure 5 showed the DNA damage induced by PpIX was greatly reduced by CsA. These results implied the DNA damage after PpIX treatment might be due to the mitochondria damage and subsequent translocation of some factors, such as AIF.

DNA damage often occurs on the upstream of cell cycle arrest. Cell cycle consists of G1, S, G2/M phases, activation of each phase depends on the proper progression and the completion of previous one. The cell cycle is highly regulated by several check-point mechanisms, which are essential for cellular responses to stresses such as DNA damage and so on [16]. In this study, S phase arrest induced by PpIX in S180 cells became more and more obvious with the increasing PpIX concentration (Table 1), and the $S$ phase cells increased from $31.62 \%$ (control) to $52.59 \%$ when PpIX was up to $40 \mu \mathrm{g} / \mathrm{ml}$ after $24 \mathrm{~h}$ of incubation. The $S$ phase arrest was also accompanied by increasing cell apoptosis (Sub-G1 peak) as PpIX dose increased at $12 \mathrm{~h}$ post PpIX-loading (Fig. 6). However, the PpIX induced S phase arrest was gradually relieved after $36 \mathrm{~h}$ and $48 \mathrm{~h}$ incubations (about two cell cycles for S180 cells), this may be due to the reduced intracellular PpIX content after prolonged incubation time.

Cyclins, CDK and CDKI are important factors in the regulation of cell cycle progression. The CDK inhibitor P21 is a key determinant in cell cycle control and apoptosis, and P21- 
Li et al.: PpIX Caused DNA Damage and Cell Cycle Arrest in S180 Cells

decient cells fail to induce cell cycle arrest following DNA damage [23]. There were reports showing that following DNA damage, p21 can be activated by its upstream p53, ensuring damaged DNA wouldn't pass to daughter cells [24, 25]. Western blots in Figure 7 showed that P53 and P21 were up-regulated in a dose-dependent manner at $24 \mathrm{~h}$ post PpIX-loading. The possible reason may be that DNA damage stimulated the expression of P53, and then further up-regulated P21. As a broad inhibitor of CDK, P21 inhibited the activity of CDK2 and slowed down DNA replication, and subsequently caused S phase cell cycle arrest.

In summary, the results showed that PpIX inhibited the proliferation of S180 cells in an incubation time- and concentration-dependent manner, induced obvious DNA damage coupling with the disruption of mitochondria membrane potential and translocation of apoptosis inducer factor from mitochondria to nucleus, and caused $S$ phase arrest with upregulation of $\mathrm{P} 53$ and $\mathrm{P} 21$.

\section{Conflict of Interest}

We all have no conflict.

\section{Acknowledgements}

This work was supported by the National Natural Science Foundation of China (Nos. 81000999, 10904087), the Research Fund for the Doctoral Program of Higher Education of China (No. 20100202110006), and the Fundamental Research Funds for the Central Universities (GK201302022).

\section{References}

1 Grebenová D, Kuzelová K, Smetana K, Pluskalová M, Cajthamlová H, Marinov I, Fuchs O, Soucek J, Jarolím P, Hrkal Z: Mitochondrial and endoplasmic reticulum stress-induced apoptotic pathways are activated by 5 -aminolevulinic acid-based photodynamic therapy in HL60 leukemia cells. J Photochem Photobiol B 2003;69:71-85.

2 Wang P, Wang X, Zhang K, Gao K, Song M, Liu Q: The spectroscopy analyses of PpIX by ultrasound irradiation and its sonotoxicity in vitro. Ultrasonics 2013;53:935-942.

- Leibovici L, Schoenfeld N, Yehoshua HA, Mamet R, Rakowsky E, Shindel A, Atsmon A: Activity of porphobilinogen deaminase in peripheral blood mononuclear cells of patients with metastatic cancer. Cancer 1988;62:2297-2300.

-4 el-Sharabasy MM, el-Waseef AM, Hafez MM, Salim SA: Porphyrin metabolism in some malignant diseases. Br J Cancer 1992;65:409-412.

5 Orenstein A, Kostenich G, Malik Z: The kinetics of protoporphyrin fluorescence during ala-pdt in human malignant skin tumors. Cancer Lett 1997;120:229-234.

-6 af Klinteberg C, Enejder AM, Wang I, Andersson-Engels S, Svanberg S, Svanberg K: Kinetic fluorescence studies of 5-aminolaevulinic acid-induced protoporphyrin IX accumulation in basal cell carcinomas. J Photochem Photobiol B 1999;49:120-128.

7 Wang X, Liu Q, Wang Z, Wang P, Zhao P, Zhao X, Yang L, Li Y: Role of autophagy in sonodynamic therapyinduced cytotoxicity in s180 cells. Ultrasound Med Biol 2010;36:1933-1946.

8 Zhu B, Liu Q, Wang Y, Wang X, Wang P, Zhang L, Su S: Comparison of accumulation, subcellular location, and sonodynamic cytotoxicity between hematoporphyrin and protoporphyrin IX in 11210 cells. Chemotherapy 2010;56:403-410.

- Wang X, Wang P, Zhang K, Su X, Hou J, Liu Q: Initiation of autophagy and apoptosis by sonodynamic therapy in murine leukemia L1210 cells. Toxicol In Vitro2013;27:1247-1259.

10 Bednarz N, Zawacka-Pankau J, Kowalska A: Protoporphyrin IX induces apoptosis in HeLa cells prior to photodynamic treatment. Pharmacol Rep 2007;59:474-479. 
Li et al.: PpIX Caused DNA Damage and Cell Cycle Arrest in S180 Cells

11 Zawacka-Pankau J, Issaeva N, Hossain S, Pramanik A, Selivanova G, Podhajska AJ: Protoporphyrin IX interacts with wild-type p53 protein in vitro and induces cell death of human colon cancer cells in a p53dependent and -independent manner. J Biol Chem 2007;282:2466-2472.

12 Li JH, Song DY, Xu YG, Huang Z, Yue W: In vitro study of haematoporphyrin monomethyl ether-mediated sonodynamic effects on C6 glioma cells. Neurol Sci 2008;29:229-235.

13 Torres K, Horwitz SB: Mechanisms of taxol-induced cell death are concentration dependent. Cancer Res 1998;58:3620-3626.

14 Murray AW: Recycling the cell cycle: Cyclins revisited. Cell 2004;116:221-234.

15 Strasser A, Harris AW, Jacks T, Cory S: DNA damage can induce apoptosis in proliferating lymphoid cells via p53-independent mechanisms inhibitable by bcl-2. Cell 1994;79:329-339.

-16 Yamauchi M, Oka Y, Yamamoto M, Niimura K, Uchida M, Kodama S, Watanabe M, Sekine I, Yamashita S, Suzuki K: Growth of persistent foci of DNA damage checkpoint factors is essential for amplification of g1 checkpoint signaling. DNA Repair (Amst) 2008;7:405-417.

17 Massague J: G1 cell-cycle control and cancer. Nature 2004;432:298-306.

18 Coqueret 0: New roles for p21 and p27 cell-cycle inhibitors: A function for each cell compartment? Trends Cell Biol 2003;13:65-70.

19 Brancaleon L, Magennis SW, Samuel ID, Namdas E, Lesar A, Moseley H: Characterization of the photoproducts of protoporphyrin IX bound to human serum albumin and immunoglobulin G. Biophys Chem 2004;109:351-360.

-20 Otera H, Ohsakaya S, Nagaura Z, Ishihara N, Mihara K: Export of mitochondrial AIF in response to proapoptotic stimuli depends on processing at the intermembrane space. EMBO J 2005;24:1375-1386.

21 Calcagnile A, Basic-Zaninovic T, Palombo F, Dogliotti E: Misincorporation rate and type on the leading and lagging strands of UV-damaged DNA. Nucleic Acids Res 1996;24:3005-3009.

-22 Zanna C, Ghelli A, Porcelli AM, Martinuzzi A, Carelli V, Rugolo M: Caspase-independent death of leber's hereditary optic neuropathy cybrids is driven by energetic failure and mediated by AIF and endonuclease G. Apoptosis 2005;10:997-1007.

23 Waldman T, Kinzler KW, Vogelstein B: P21 is necessary for the p53-mediated g1 arrest in human cancer cells. Cancer Res 1995;55:5187-5190.

24 Schuler M, Maurer U, Goldstein JC, Breitenbucher F, Hoffarth S, Waterhouse NJ, Green DR: P53 triggers apoptosis in oncogene-expressing fibroblasts by the induction of noxa and mitochondrial bax translocation. Cell Death Differ 2003;10:451-460.

25 Chipuk JE, Kuwana T, Bouchier-Hayes L, Droin NM, Newmeyer DD, Schuler M, Green DR: Direct activation of bax by p53 mediates mitochondrial membrane permeabilization and apoptosis. Science 2004;303:10101014. 